\title{
US scientists rally behind funding bill
}

Sir — Read the Nature editorial, "Think of a number and double it", and you will conclude that scientists have lost their savvy - or at least their ability to crunch numbers (Nature 393, 1; 1998). The object of your criticism was the National Research Investment Act of 1998, which has drawn 17 bipartisan co-sponsors in the US Senate and represents many of the sentiments of the unified statement on research supported by the leaders of 110 science, engineering and mathematics organizations. Recognizing the extraordinary importance of science and engineering for the future of the nation, the bill would authorize doubling the federal investment in civilian research over a ten-year period.

As supporters of the legislation, we take strong issue with the facts presented in the editorial and with its logic. The bill, known as $\mathrm{S1305}$, was submitted last fall by Senators Phil Gramm (Republican, Texas), Joseph Lieberman (Democrat, Connecticut), Peter Domenici (Republican, New Mexico) and Jeff Bingaman (Democrat, New Mexico). It aims to accomplish three goals: to help stanch the research budget haemorrhaging of recent years; to raise the visibility of science and engineering within the Senate; and to put the White House on notice that Congress, too, has a strong and enduring interest in the science and technology issue.

The bill has already achieved a measure of these three goals. Last February, the president delivered a strong budget recommendation on science for fiscal year 1999. In March, the Senate wrote a budget resolution that identifies science as a priority and recently followed that with appropriations allocations that provide opportunities for science account increases. Finally, 17 co-sponsors have joined the bill, and many other senators have become more aware of the nexus between federal research investments and our national prosperity.

The bill has also served as a rallying point for the entire science and engineering community. It has drawn the disparate parts together. And it has made it possible for scientists and engineers around the country to make their case to the public. To date, at least five major newspapers have carried editorials that emphasize the importance of research to the nation's future and to the economic vitality of individual states and localities, all based on the premise of S1305.

To assert, as your editorial does, that S1305 simply carries the message 'spend' is to miscast the role of the bill. The legislation follows a time-honoured tradition of sending a message to congressional appropriators that their colleagues want an issue to be taken seriously - in this case research. You seem to have misunderstood how the process works.

Nature's criticism of S1305 also suffers from a serious logical flaw. You assert that the bill's $\$ 170$ billion ten-year price tag has not been justified. But you also note that the case has been made convincingly for the
National Science Foundation and the National Institutes of Health (NIH), two agencies that Congress and the White House strongly support. Yet it is the activities of these two agencies that account for most of the growth.

The strength of American science and engineering lies in the multiplicity of agency support. At a time when science and engineering have become so thoroughly interdependent, maintaining the health of this structure takes on even greater significance. Representative John Porter (Republican, Illinois), chairman of the House appropriations subcommittee that oversees the NIH, stated at a hearing on 20 May: "Just as we don't want to set disease against disease, neither do we want to set one science against another.... All have to be valued and brought along at a relatively equal pace." Those are the goals of S1305, with which we concur. We are mystified that you seemed not to share this view.

\section{Martha Sloan (Chair)}

American Association of Engineering Societies, 1111 19th Street, NW, Washington, DC 20036, USA Arthur Jaffe (President)

American Mathematical Society,

1527 18th Street, NW, Washington, DC 20036, USA

Paul Walter (President)

American Chemical Society,

1155 16th Street, NW, Washington, DC 20036, USA

Andrew M. Sessler (President)

American Physical Society,

One Physics Ellipse, College Park, MD 20740, USA

\section{Combinatorial chemistry} in the hunt for medicines

Sir - Your feature on bioprospecting (Nature 392, 535; 1998) conveys a misleading impression of combinatorial libraries: "At present, all these synthetic molecules are polymers". Although early libraries were mainly based on peptides and nucleotides, the current focus ${ }^{1}$ is on 'small molecules' that are not polymeric and have drug-like physicochemical properties.

I have previously pointed out a fundamental difference between combinatorial chemistry and natural product screening: "At the present time, libraries are constructed by short sequences of synthetic transformations, whereas natural products are the results of much longer and more creative pathways" 2 . Libraries would approach the structural intricacy of natural products if combinatorial syntheses of ten or more steps were practical. Given the current pace of development, this may well be possible in the future. It is not just a question of increased efficiency, though — chemists string together familiar reactions, while nature is adept at assembling unusual ring skeletons and functional groups.

For example, the chemistry of betalactams and enediynes was virtually unknown until their presence was recognized in antibiotics. However, complexity is not always necessary nor desirable. Many medicines are made in a few steps by straightforward reactions, and there is no reason why combinatorial chemistry in its present state cannot lead to many more such drugs.

Anyone engaged in natural product screening will be painfully aware of its bottlenecks. Improvements occur in small increments, unlike the exponential progression of combinatorial chemistry which has led to its enthusiastic reception by the pharmaceutical industry.

The major effect of such comparisons has been to provide a long overdue push to innovate and revolutionize the process of natural product screening, which will ultimately benefit drug discovery as a whole.

\section{A. Ganesan}

Institute of Molecular and Cell Biology,

30 Medical Drive, Singapore 117609

1. Balkenhohl, F., von dem Bussche-Huennefeld, C., Lansky, A. \&
Zechel, C. Agnew. Chem. Int. Ed. Engl. 35, 2288 (1996).
2. Ganesan, A. Agnew. Chem. Int. Ed. Engl. 35, 611 (1996).

Call for change in Brazil

Sir - Fernando C. Reinach addresses important questions on science and technology development in Latin American countries (Nature 392, 647-648; 1998).

A big drawback in our public universities in Brazil is that salaries are not based on productivity. Whether one likes it or not, that is unrealistic in present times. Unfortunately, corporatism is so strong and entrenched in Brazil's academic community that change will only happen if imposed by the government. This, of course, will provoke strikes, and waste time and money.

The problem is that, the more the 
academic community resists change, the greater is the risk of losing support from society, and therefore of the flowering of private, profit-making universities. This will have severe consequences for science. Eurico C. de Oliveira

Instituto de Biociencias, Universidade de São Paulo, Cpostal 11461, 05422-970 São Paulo, SP, Brasil

\section{Scientists at the sharp end in a disaster zone}

Sir - In a News item (Nature 392, 743-744; 1998), you discuss the role of scientists in the management of the Montserrat volcano crisis, on the basis of the verbal presentation of an unpublished study at a meeting.

This study appears to rely mainly on the findings of a student's research project that covered a few months of this prolonged emergency (now nearing three years duration). As far as the Montserrat Volcano Observatory is concerned, the study and visit had no official standing at the time, and was conducted outside the ambit of any of the emergency organizations operating in Montserrat. This work is, as yet, unrevealed for scrutiny and it remains to be seen whether the methods used were robust and reliable, particularly in respect of canvassing accurate opinions from a complex West Indian society under stress. This perspective has been given prominence and currency by your report and, by publishing unsubstantiated assertions about the conduct of the crisis, there is a danger of misleading your readers. On behalf of the scientists who have worked at the observatory throughout the crisis, we reject the main thrust of the piece, and many of its inferences.

Strong emphasis is placed in the report on "predictions" during the eruption, and the ways in which they are purported to have failed. Throughout the crisis, the observatory's scientists have been providing descriptive and probabilistic scenarios of potential eruptive activity over various timescales, using layman's terms as far as possible. They have not, at any time, offered public predictions in any accepted scientific sense of the term. The vast majority of the population developed a sound understanding of the eruption and its implications, and quickly accepted that many aspects of volcanic phenomena are unpredictable.

The examples of supposed predictions cited in the article are either inappropriate or incorrect. For instance, the authorities and the public had been repeatedly advised that explosions, such as that of 17 September 1996, could occur with little or no warning. The heightened alert that accompanied the strong eruptive activity on
19 December 1996 was not a failed prediction. What happened was that observed activity, such as seismicity buildup and ongoing dome collapse, exceeded thresholds for raising the alert level, agreed previously with the civil authorities to indicate a state requiring precautionary evacuation of selected areas. To term this a "false alarm" is tendentious — the warning signs, and official concern, were real and had to be acted upon.

The scientists of the observatory team have provided timely hazard appraisals and detailed risk mitigation strategies, using modern methods of structured assessment, and their work has recently been scrutinized by a House of Commons select committee and by a group chaired by the UK government's chief scientific adviser. In addition to their arduous and often dangerous scientific investigation of the eruption, the team has sustained a public outreach effort probably unsurpassed in any previous volcanic emergency. There is a wealth of documentary evidence about the public's understanding and response to the scientific component of this emergency, which will become increasingly available once the crisis has subsided, and upon which a balanced and complete account of the observatory's contribution to the management of the Montserrat eruption can be based. Only then can successes or shortcomings be rationally judged.

In particular, all the factors surrounding the 19 fatalities on 25 June 1997 (and two others later on) are yet to be fully elucidated and appraised. We wish to stress that scientific warnings had been issued (or acted upon) between December 1996 and June 1997. Although some people had been allowed back into certain areas after the December activity subsided, a reevacuation and extended exclusion zone were implemented well before the big dome collapse occurred. All the casualties occurred within that exclusion zone, in areas that had been clearly identified as high risk. This casualty toll should be placed in its wider context: at the outset of the crisis in July 1995, when many in Montserrat were unaware that the Soufriere Hills was an active volcano, there were about 7,000 people living and working in areas that are now buried by pyroclastic flows or obliterated by violent surges. Their lives were successfully protected, albeit at great personal cost and privation.

In an editorial (Nature 388, 1; 1997), you used the tragic events of 25 June 1997 to enjoin scientists confronting natural disasters to co-operate more closely with social scientists. In principle, this is a sensible proposal, and worthwhile if there is scope for achieving real benefit. But in a free society there will always be individuals who will not heed advice or instructions to avoid hazardous situations such as those on the flanks of an erupting volcano. This was a major factor in the Montserrat fatalities, not the minutiae of communications between scientists and the public. Many people put themselves in danger attempting to convince the victims to leave those areas and, in terms of any scientific function, it is not clear what more could have been done to avert these casualties.

The fact that a significant number of individuals may knowingly choose to accept extreme levels of risk to remain in a danger zone will present a major challenge for societal risk management at volcanoes elsewhere. A careful, collaborative analysis of all the experience from the Montserrat crisis is merited, not a unilateral and illconsidered rush to judgement. Your article and its shortcomings are, therefore, at best unhelpful, and may actually discourage hard-pressed scientists (endeavouring to help protect life and limb) from engaging with colleagues from the social sciences in any similar safety-critical situation.

Willy Aspinall, Peter Francis, Lloyd Lynch, Richard Robertson, Keith Rowley, Steve Sparks, Simon Young and others Montserrat Volcano Observatory, St Johns, Montserrat, West Indies e-mail:mvo@candw.ag

Sir - A recent News story about the earthquake on Montserrat referred to a report with which I was involved (Nature 392, 743-744; 1998). The thrust of our findings was that the scientists involved have been in the unenviable position of $d e$ facto disaster managers, a role for which they were not trained nor, it could be argued, should have been involved in.

There has therefore been an additional burden to their already complex and difficult task of being both authors and messengers of volcanic forecasting and warning. It should be recognized that, if the scientists had not been involved, the death toll on the island would have certainly been higher. Their role has been one of crisis management in extreme circumstances.

It was not part of our findings that many residents felt "the scientists' prediction record was sometimes no better than their own". Although one or two may have held this view, this generalization was not made. The credibility of the scientists has generally been high throughout the crisis; indeed, the constant focus on the scientists' activities would appear to be one of the major contributing pressures on them. The project was funded by the UK Department for International Development as part of a two-year project looking at forecasting and warnings in four parts of the world.

\section{David Sanderson}

154 Banbury Road, Kidlington,

Oxford OX5 2BY, UK 